\title{
Demographic, clinical, and pathological features of early onset pancreatic cancer patients
}

\author{
Chara Ntala', Silvana Debernardi ${ }^{1}$, Roger M. Feakins ${ }^{2}$ and Tatjana Crnogorac-Jurcevic ${ }^{1 *}$ (D)
}

\begin{abstract}
Background: Early onset pancreatic cancer (EOPC), i.e. pancreatic ductal adenocarcinoma (PDAC) occurring in patients below 50 years of age, is rare and there is limited information regarding risk factors, molecular basis and outcome. This study aimed to determine the demographic and clinicopathological features and survival figures for EOPC.

Methods: A retrospective analysis of patients treated at the Royal London Hospital for PDAC between September 2004 and September 2015 was performed. Data on demographics, risk factors, presentation, pathological features, treatment and survival outcome were compared in EOPC and older PDAC patients.

Results: Of 369 PDAC cases identified, 35 (9.5\%) were EOPC. Compared to older patients, EOPC patients were more frequently male ( $71 \%$ vs $54 \%, p=0.043$ ) and less commonly of British origin ( $37 \%$ vs $70 \%, p=0.002)$. There was no significant difference regarding the prevalence of any of the risk factors known to be associated with older PDAC patients. Fewer EOPC patients presented with resectable disease ( $23 \%$ vs $44 \%, p=0.015)$ and more received adjuvant chemo/radiotherapy ( $60 \%$ vs $46 \%, p=0.008$ ). The overall median survival and stage specific survival did not differ significantly between the two groups, although a longer survival for localized disease was seen in EOPC patients (25 months (12.9-37, 95\%Cl) vs 13 months (10.5-15.5 95\%Cl) for older PDAC patients).

Conclusions: The EOPC patients had different demographics and were more likely than their older PDAC counterparts to be male. Typically they presented with more advanced disease, received more aggressive treatment, and had on overall similar survival outcome.
\end{abstract}

Keywords: EOPC, Early onset, Pancreatic cancer, Risk factors, Survival

\section{Background}

Pancreatic ductal adenocarcinoma (PDAC) is the most common pancreatic malignancy. It is the fourth leading cause of cancer death with a 7\% five-year survival rate in the United States [1], and is predicted to be the second cause of cancer-related death by 2030 [2]. The mean age of PDAC patients at presentation is 71 years [3]; however, $5-10 \%$ of these patients are diagnosed with this malignancy at a young age, when they are less than 50 years old [4-7]. This important subgroup of PDAC patients, often referred to as early onset pancreatic cancer (EOPC), has been poorly studied, and the cause of

\footnotetext{
* Correspondence: t.c.jurcevic@qmul.ac.uk

${ }^{1}$ Barts Cancer Institute, Queen Mary University of London, John Vane Science

Centre, Charterhouse Square, London EC1M 6BQ, UK

Full list of author information is available at the end of the article
}

such an early presentation of the disease remains unknown [6, 8-14].

PDAC is considered to be more frequent in individuals with familial history [15-18] and hereditary genetic syndromes, such as Hereditary Pancreatitis (HP) [19-21], Lynch syndrome [22] and Peutz-Jeghers syndrome $[23,24]$. Modifiable risk factors include tobacco exposure, alcohol use, chronic pancreatitis, diabetes mellitus, diet, obesity, previous radiotherapy, as well as certain types of abdominal surgery and infections [25-33]. Also, an inverse association between PDAC and atopic diseases has been identified [34].

In this report, we provide the data of a comprehensive and systematic study on demographics and known PDAC risk factors, as well as detailed clinicopathological, treatment and outcome figures for EOPC patients.

(C) The Author(s). 2018 Open Access This article is distributed under the terms of the Creative Commons Attribution 4.0 International License (http://creativecommons.org/licenses/by/4.0/), which permits unrestricted use, distribution, and 
The study comprised retrospective examination of notes on PDAC patients collected over the 11-year period between September 2004 and September 2015, from one of the major Hepato-Pancreato-Biliary (HPB) referral hospital centres in London, UK. We compared these data to the data collected for the older PDAC patients from the same centre in order to identify differences and potentially suggest clues to the biology of the disease.

\section{Methods}

\section{Database search and data extraction}

We conducted a search of the pathology archives and patients' database at the Royal London Hospital for period between 18/9/2004 to 18/9/2015 in order to identify patients who were diagnosed with pancreatic ductal adenocarcinoma. We used the topography search codes "pancreatic structure" and "pancreas and duodenum", and included pancreatic FNAs (fine needle aspirations), core biopsies and surgical resection specimens with a pathology diagnosis of pancreatic ductal adenocarcinoma or adenocarcinoma with features "compatible with", "suggestive of" or "typical of" pancreatic ductal origin. We excluded all other histologic subtypes and cases of adenocarcinoma of unknown origin, highly suspicious of adenocarcinoma, adenocarcinoma arising from ampulla or bile duct and non-neoplastic diagnoses (Fig. 1). Patients under the age of 50 were grouped into the EOPC cohort and were compared to older patients, referred to here as the older PDAC group. Information extracted consisted of the following: 1) Demographics: age, gender and ethnicity. 2) Epidemiologic and genetic information: history of alcohol excess, obesity $(\mathrm{BMI}>30)$, previous abdominal surgery or radiotherapy, allergy status, and family history of pancreatic cancer or other related malignancies. Specific quantitative data on smoking history in terms of duration, intensity, or recency were rarely available thus smoking history was descriptive (never/ex/ current smoker) rather than in accordance with specific definitions (e.g. pack-years). 3) Presenting symptoms: Past medical history of chronic pancreatitis was considered positive if it was present more than 6 months before diagnosis, and recent onset diabetes mellitus was defined as diabetes diagnosed within 3 years before diagnosis. 4) Clinical stage at diagnosis: record followed the American Joint Committee on Cancer (AJCC) and the Union for International Cancer Control (UICC) TNM staging system 7th edition [35]. 5) Surgical management, details of adjuvant and palliative treatment. 6) Survival data. The date of diagnosis was defined as the date when biopsy was taken. The date of last follow-up was used if date of death was not available. The study was done under Research Ethics approval (Reference Number: 05/ Q0408/65).

\section{Statistical analysis}

Differences between groups were calculated with two-sided chi-square test $(p<0.05$ was considered statistically significant). The age was presented as a mean

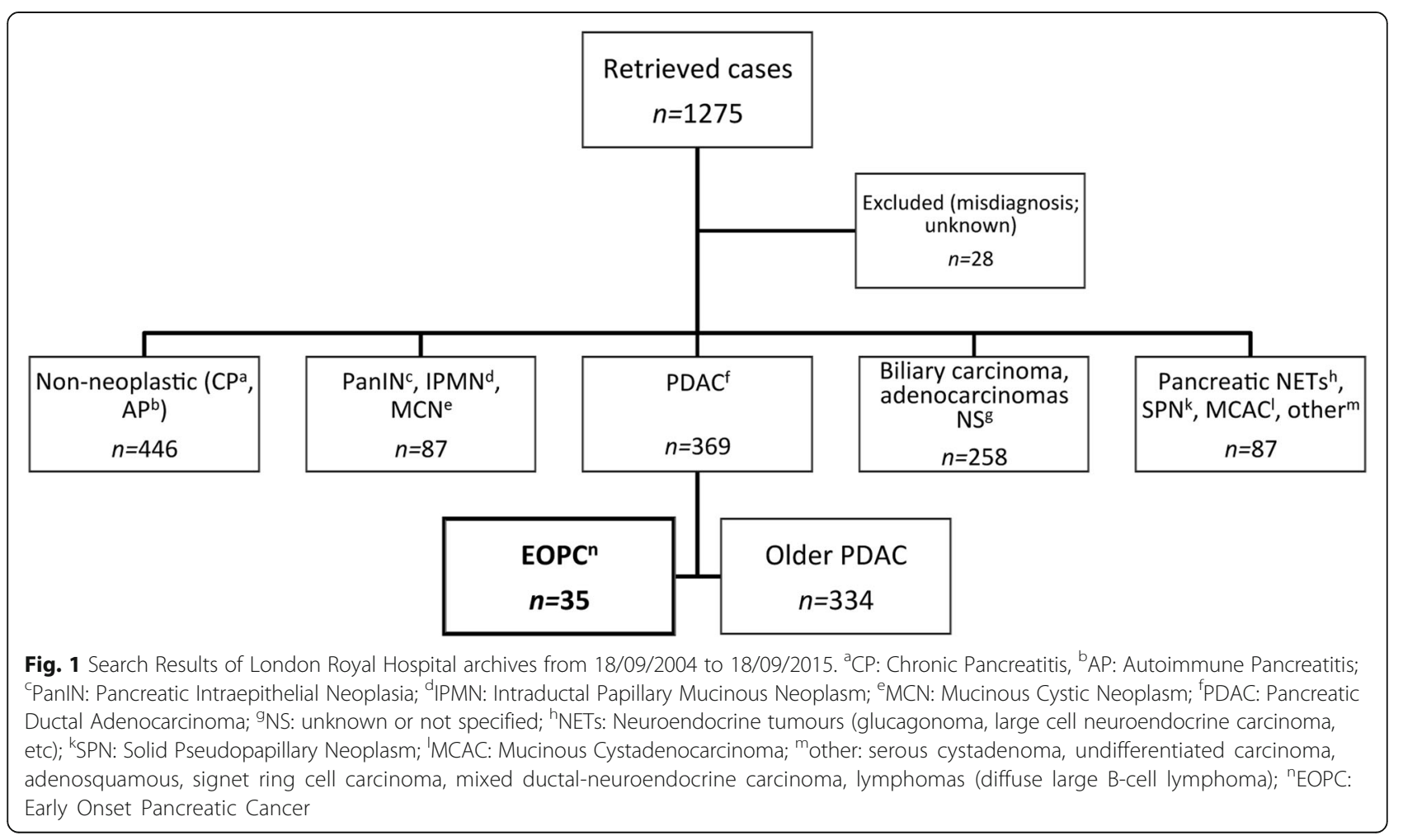


value with ranges, and survival was presented as a median value with $95 \%$ confidence intervals (CI). Survival curves were estimated using the Kaplan-Meier method and compared by the log-rank test. All statistical analyses were performed using IBM SPSS Statistics 24.0.

\section{Results \\ Patient demographics, epidemiologic and genetic characteristics}

Our search identified 1275 cases; of 369 pancreatic cancer cases 35 were EOPC, comprising $9.5 \%$ of the total PDAC population (Fig. 1). The general characteristics of EOPC and older PDAC patients are presented in Table 1. The mean age was 45.71 (33 to 50) years for the young onset population while older PDAC patients had a mean age of 66.19 (51 to 85) years. Gender distribution was significantly different between EOPC and older PDAC groups, with higher rate of male patients in the younger cohort $(71 \%$ vs $54 \%, p=0.043)$. In terms of ethnicity, the majority of older PDAC patients were British $(70 \%$ vs $37 \%$ in EOPC cohort, $p=0.002$ ), whereas the EOPC group included a significant proportion of patients from Asian and Central/Eastern European origin. There was no significant difference in terms of modifiable and genetic risk factors between the two groups. First-degree family history in the EOPC cohort is presented in Table 2. Only one of the 35 EOPC patients was affected by a genetic syndrome (Lynch syndrome). Four EOPC (11\%) patients and 34 older PDAC patients $(10 \%)$ had a first-degree relative with history of any type of cancer $(p=0.989)$. None of the EOPC and only $12(4 \%)$ of the older PDAC patients had a first-degree relative with pancreatic cancer $(p=0.25)$. Interestingly, one EOPC patient had two 2nd degree relatives from parental side (an uncle and a cousin) also diagnosed with pancreatic cancer at an early age (50 and 49 years, respectively).

\section{Symptoms at presentation}

With regards to symptoms at presentation, obstructive jaundice was the most frequent presenting symptom in both groups, followed by anorexia, abdominal pain, nausea and vomiting. Two EOPC (6\%) patients presented with early onset diabetes compared to 40 PDAC (12\%) patients $(p=0.299)$.

\section{Pathology and clinical stage at diagnosis}

A significantly lower number of EOPC patients (22.9\%) presented with localised resectable disease compared to older PDAC patients $(44 \%)(p=0.015)$. A similar proportion of EOPC (54\%) and older PDAC (42\%) patients had locally advanced unresectable disease or presented with distant metastases (23\% vs $17 \%)$. In EOPC, half of the patients with metastases at diagnosis had a single liver metastasis and the other half had more than one site of metastasis. The most common sites of metastatic disease were liver (75\%), lung (37.5\%), pleura and omentum (12.5\% each). Similarly, in older PDAC patients the most common site of metastasis was liver, occurring alone in just above half of the cases (53.5\%) and in combination with other sites in a further $15.5 \%$ of tumours. Other single sites were lung (7\%), peritoneum (7\%), omentum (1.7\%) and pleura (1.7\%). Tumour grading and AJCC/ UICC TNM stage of EOPC and older PDAC patients did not differ, and there was no significant difference in terms of the other pathological characteristics of tumours (location, differentiation, stage, perineural invasion and vascular invasion) between the two groups (Table 3).

\section{Treatment and survival}

All 8 (22.9\%) EOPC and 147 (44\%) PDAC patients with localised disease underwent resection with curative intent. The AJCC/UICC TNM stage of EOPC patients who underwent resection was as follows: IA $(n=2)$, IIA $(n=1)$, IIB $(n=5)$. Sixty per cent of EOPC patients received adjuvant or palliative chemotherapy/radiotherapy whereas only $46 \%$ of the older PDAC patients were fit enough to receive the same treatment $(p=0.008)$ (Table 3). Six (17.4\%) EOPC and 77 (23\%) PDAC patients received a combination of chemotherapy/radiotherapy and surgery with curative intent, out of which one (16.7\%) EOPC and six (7.8\%) PDAC received this as neoadjuvant treatment that down-staged their disease. The median overall survival of the EOPC patients (12 months, $5-18.9,95 \% \mathrm{CI}$ ) was higher than in older PDAC patients (9 months, 7.8-10.2, 95\% CI) and there was also a trend towards increased stage specific survival ( 25 vs to 13 months) but neither difference was statistically significant (Fig. 2 and Table 4). Similarly, for patients with locally advanced disease, the median overall survival was 11 months (3.9-18.1, 95\%CI) for the EOPC patients and 8 months (6.5-9.4, $95 \% \mathrm{CI})$ for the older PDAC patients $(p=0.172)$. Regarding patients with metastatic disease, both cohorts had a median survival of 6 months $(p=0.213)$ (Table 4$)$.

\section{Discussion}

In this study, we performed a detailed retrospective analysis of EOPC patients with histologically confirmed PDAC in the setting of one of the largest HPB centres in the United Kingdom. While previous EOPC reports also included patients with pathological "variants" (e.g. mucinous cystic neoplasms) which are not included in the current WHO classification of pancreatic ductal adenocarcinoma, our report is based on the most recent PDAC classification and staging. We have used 50 years as the cut-off age for EOPC patients, which, although arbitrary, has been used previously [4-7]. A detailed summary of comparisons between different EOPC studies is 
Table 1 EOPC and older PDAC demographics, past medical history, environmental and genetic risk factors

\begin{tabular}{llll}
\hline Characteristics & $\begin{array}{l}\text { EOPC (35), \% } \\
\text { ( } \leq 50 \text { years) }\end{array}$ & $\begin{array}{l}\text { PDAC (334), \% } \\
\text { (>50 years) }\end{array}$ & $p$ value \\
\hline $\begin{array}{l}\text { Mean Age } \\
\text { (Range in years) }\end{array}$ & 45.71 & 66.19 & \\
Gender & $(33$ to 50$)$ & $(51$ to 85$)$ & \\
$\quad$ & & & 0.043 \\
$\quad$ Male & $25(71 \%)$ & $179(54 \%)$ & \\
$\quad$ Female & $10(29 \%)$ & $155(46 \%)$ & \\
Ethnicity & & & 0.002
\end{tabular}

$\begin{array}{lll}\text { British } & 13(37 \%) & 233(70 \%) \\ \text { Asian } & 5(14 \%) & 9(3 \%) \\ \text { Black } & 3(9 \%) & 22(7 \%) \\ \text { Other white background } & 4(11 \%) & 11(3 \%) \\ \text { Any other group } & 2(6 \%) & 12(4 \%) \\ \text { Missing } & 8(23 \%) & 47(14 \%)\end{array}$

Smoking status

Current smoker

Ex-smoker

No

Missing

History of alcohol excess

Yes
No
Missing
Obesity

Yes
No
Missing

Genetic syndrome

Yes

No

Missing

History of chronic pancreatitis

Yes

No

Missing

History of diabetes

Yes

No

Missing

Allergy $^{\mathrm{a}}$

Yes

No

Missing

Previous radiotherapy

Yes
Table 1 EOPC and older PDAC demographics, past medical history, environmental and genetic risk factors (Continued)

\begin{tabular}{llll}
\hline Characteristics & $\begin{array}{l}\text { EOPC (35), \% } \\
\text { ( } \leq 50 \text { years) }\end{array}$ & $\begin{array}{l}\text { PDAC (334), \% } \\
(>50 \text { years) }\end{array}$ & $p$ value \\
\hline No & $23(66 \%)$ & $261(78 \%)$ & \\
Missing & $11(31 \%)$ & $59(18 \%)$ & \\
Previous abdominal surgery ${ }^{b}$ & & & 0.056 \\
Yes & $9(26 \%)$ & $78(23 \%)$ & \\
No & $9(26 \%)$ & $194(58 \%)$ & \\
Missing & $17(49 \%)$ & $62(19 \%)$ & \\
\hline
\end{tabular}

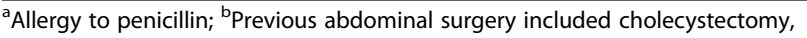
lateral pancreaticojejunostomy

shown in Table 5. The main differences between the two PDAC groups were seen in demographic data. EOPC patients in our population were more frequently males, in agreement with previous studies [5-7, 12, 13, 36, 37]. In addition, our EOPC patients were less frequently of white British background and more commonly Asian or from 'any other white background'. The latter comprised mainly Central and Eastern Europeans. Similar findings were reported by Raimondi et al. who demonstrated in a worldwide study a higher number of male than female patients and a peak in Central and Eastern European countries followed very closely by Asian countries [28]. The association of gender and race/ethnic group with incidence of pancreatic cancer has also been documented in a US report conducted by the National Cancer Institute, where the authors showed the higher incidence and mortality rate in men than in women in each racial/ethnic group, between the age of 30 and 54 [38]. Miller et al., showed up to $50 \%$ higher incidence and mortality rate in the black compared to the white population, for the same age group (30-54 years) [38].

One of the putative explanations for the higher incidence of EOPC in males is smoking, a known independent risk factor for pancreatic cancer in all age groups $[3,7,28,30,39,40]$. Indirect association of EOPC and smoking in males was first highlighted by Raimondi et al. who correlated the higher EOPC male/female ratio positively with an early onset of

Table 2 Family history of cancer in EOPC patients

\begin{tabular}{ll}
\hline EOPC patients & Family history of cancer \\
\hline 1 & Mother: endometrial cancer \\
2 & Mother: colon and endometrial cancer, \\
& mAunt: endometrial cancer, pGrandmother: \\
& bowel cancer, pCousin: breast cancer (age 32), \\
& Grandmother: stomach cancer ${ }^{a}$ \\
3 & Father: esophageal cancer, Brother: colon cancer, \\
& Sister: esophageal cancer \\
4 & Sister: lung cancer (age 38) \\
\hline p: paternal, m: maternal, ${ }^{a}$ Lynch syndrome
\end{tabular}


Table 3 EOPC and older PDAC tumour characteristics and treatment details

\begin{tabular}{|c|c|c|c|}
\hline Tumour Characteristics & $\begin{array}{l}\text { EOPC }(N=35), \% \\
(\leq 50 \text { years })\end{array}$ & $\begin{array}{l}\text { PDAC }(N=334), \% \\
(>50 \text { years })\end{array}$ & $p$ value \\
\hline Resectable & & & 0.015 \\
\hline Yes & $8(22.9 \%)$ & 147 (44\%) & \\
\hline No & $27(77.1 \%)$ & $186(56 \%)$ & \\
\hline Missing & 0 & $1(0 \%)$ & \\
\hline Location & & & 0.579 \\
\hline Head/Uncinate & 27 (77\%) & 265 (79\%) & \\
\hline Body/Tail & $8(23 \%)$ & $62(19 \%)$ & \\
\hline Missing & 0 & $7(2 \%)$ & \\
\hline Differentiation grade & & & 0.315 \\
\hline Well & $2(6 \%)$ & $15(4 \%)$ & \\
\hline Moderate & $16(46 \%)$ & $127(38 \%)$ & \\
\hline Poor & 12 (34\%) & 170 (51\%) & \\
\hline Missing & $5(14 \%)$ & $22(7 \%)$ & \\
\hline Stages & & & 0.194 \\
\hline । & $2(5.8 \%)$ & $16(5 \%)$ & \\
\hline$\|^{*}$ & $6(17.1 \%)$ & $117(34 \%)$ & \\
\hline III & $19(54.2 \%)$ & $140(42 \%)$ & \\
\hline IV & $8(22.9 \%)$ & $57(17 \%)$ & \\
\hline Missing & 0 & $4(1 \%)$ & \\
\hline Perineural invasion & & & 0.348 \\
\hline Yes & $12(34 \%)$ & $142(43 \%)$ & \\
\hline No & $23(66 \%)$ & $192(57 \%)$ & \\
\hline \multicolumn{4}{|l|}{ Perivascular invasion } \\
\hline Yes & 7 (20\%) & $122(37 \%)$ & 0.051 \\
\hline No & $28(80 \%)$ & $212(63 \%)$ & \\
\hline $\begin{array}{l}\text { Chemotherapy/ } \\
\text { radiotherapy }\end{array}$ & & & 0.008 \\
\hline Yes & $21(60 \%)$ & $153(46 \%)$ & \\
\hline No & $5(14 \%)$ & $131(39 \%)$ & \\
\hline Missing & $9(26 \%)$ & $50(15 \%)$ & \\
\hline
\end{tabular}

*Stage II $p$ value $=0.032$

lung cancer $(<50$ years of age) [28]. Direct association was provided by Piciucchi et al. [7], who, based on patient interviews, demonstrated a significantly increased risk of EOPC among the 'current smokers' group and a positive correlation with the 'young age at smoking initiation' [7]. In our cohort, however, only $31 \%$ of the total EOPC population had a smoking history which was comparable to the older PDAC cases $(29 \%)$.

Interestingly, the highest incidence of EOPC patients was reported in two independent studies conducted in North Africa, in Morocco [36] and Egypt [41]: 17\% of PDAC patients were younger than 45 years in Morocco [36], and almost $25 \%$ in the East Nile Delta were under the age of 50 [41]. In both countries the male to female ratio was around 2:1, in accordance with other reports. Regarding smoking, in the Moroccan population only $12.5 \%$ of all EOPC patients were smokers [36]. In contrast, in Egypt smoking is highly prevalent (40\% of the general population are smokers). While the authors do not report the smoking history of the EOPC patients, they speculate that occupational and environmental exposure to heavy metals like cadmium, nickel and chromium, as well as other polluting chemicals, could contribute to the high incidence of EOPC in this heavily industrialised region [41]. Unfortunately, we do not have any information on environmental exposure of our study population, and the effect of pollution on our Londonbased patients would be interesting to explore.

Our study did not identify any differences between EOPC and older PDAC patients in any of the previously identified risk factors for PDAC, i.e. alcohol intake, obesity, history of chronic pancreatitis, history of diabetes, previous abdominal surgery and previous radiotherapy. The rate of recent onset diabetes was somewhat lower in EOPC (6\% EOPC vs $12 \%$ PDAC, $p=0.299$ ) although this was not statistically significant.

None of the patients in our EOPC cohort met the criteria for a familial pancreatic cancer syndrome [42]. Four of the EOPC patients in our cohort had a family history of any cancer but none had a first-degree relative with pancreatic cancer, and only one patient had a hereditary genetic syndrome (Lynch Syndrome) associated with increased risk of pancreatic cancer [22]. A similarly low incidence of familial cases, with no significant difference between young and old PDAC groups, has been reported in other studies. In the cohort described by Duffy et al. [10], only $2.2 \%$ of EOPC patients had a family history of pancreatic cancer and no EOPC patients were affected by any of the hereditary syndromes. Tingstedt et al. [5] reported 3\% of EOPC with a first-degree relative with pancreatic cancer. However, somewhat higher incidences were found by Piciucchi et al. [7] in both young and older patients, where $8 \%$ and $6.3 \%$ of cases respectively had a family history of pancreatic cancer. A recent study by Ohmoto et al. [37] suggests a lack of association between hereditary genetic factors and EOPC. The authors assessed the mutation status of 49 genes involved in hereditary syndromes in the germline of EOPC patients younger than 40 years, but did not find any variants [37]. In contrast, James et al. [17] reported an overall incidence of familial pancreatic cancer of $3 \%$, with the percentage of patients $\leq 50$ years of age being significantly higher than among the sporadic cancer patients $(36 \%$ and $18.3 \%$, respectively, $p=0.017$ ). Overall, the underlying factors influencing the young onset of pancreatic cancers remain to be determined. 


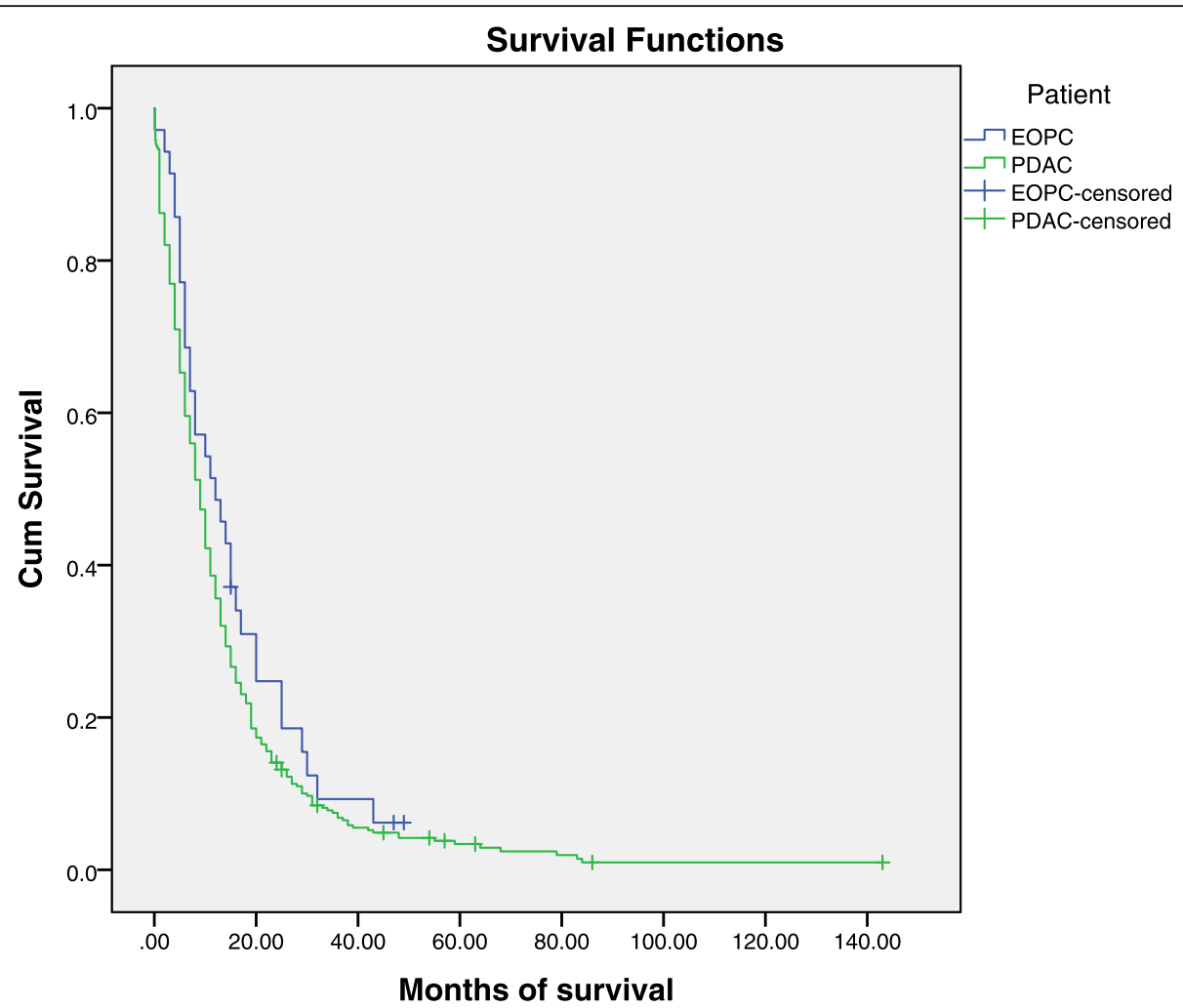

Fig. 2 Kaplan Meier overall survival curve in EOPC and older PDAC patients. ( $y$-axis: Cum Survival (cumulative survival), $x$-axis: time in months)

In our study, the presenting symptoms (obstructive jaundice, abdominal pain, and change in bowel habit, nausea /vomiting, anorexia or weight loss) were largely shared between the two cohorts, and both young and old PDAC patients most commonly presented with obstructive jaundice, probably due to a high incidence of lesions located in the pancreatic head. Interestingly, in a study by Piciucchi et al. [7], jaundice at presentation occurred in only $16 \%$ of the EOPC patients, a significantly lower rate than in older PDAC patients $(44 \%, p=0.06)$ [7]. This was probably due to a lower rate of tumours located in the head of the pancreas ( $64 \%$ vs $83 \%, p=0.03$ ). Jiang et al. [13] also reported a low frequency of jaundice in EOPC patients, although this could not be explained by tumour location.

Table 4 Overall survival (in months) of EOPC and older PDAC cohorts

\begin{tabular}{llll}
\hline & \multicolumn{2}{l}{ Median survival (months) } & \\
\cline { 2 - 3 } & $\begin{array}{l}\text { EOPC }(N=35) \\
(\leq 50 \text { years })\end{array}$ & $\begin{array}{l}\text { PDAC }(N=334) \\
(>50 \text { years })\end{array}$ & \\
\hline Entire cohort $^{\mathrm{a}}$ & $12(5-18.995 \% \mathrm{Cl})$ & $9(7.8-10.295 \% \mathrm{Cl})$ & 0.168 \\
Stage I-II & $25(12.9-3795 \% \mathrm{Cl})$ & $13(10.5-15.595 \% \mathrm{Cl})$ & 0.307 \\
Stage III & $11(3.9-18.195 \% \mathrm{Cl})$ & $8(6.5-9.495 \% \mathrm{Cl})$ & 0.172 \\
Stage IV & $6(3.2-8.895 \% \mathrm{Cl})$ & $6(4.8-7.295 \% \mathrm{Cl})$ & 0.213 \\
\hline
\end{tabular}

${ }^{\mathrm{a}}$ Data missing for three EOPC and nine PDAC patients
The two groups also showed similar pathological characteristics. Poorly differentiated tumours tended to be more common in older PDAC patients (34\% vs 51\%) and moderately differentiated in EOPC (46\% vs $38 \%$ ), but this was not statistically significant. Furthermore, no difference was observed in the rates of perineural and vascular invasion. Other studies have also showed that the pathological features in EOPC patients are similar to those seen in older PDAC patients, $[8,9]$ although the presence of more histological variants, especially mucinous carcinomas, has been observed in EOPC cases [8]. Interestingly, a lower rate of KRAS mutations in EOPC patients was found in two studies, $[9,43]$, although both were performed on a small number of cases (five and seven, respectively).

In our data, EOPC patients presented at a more advanced stage compared to older PDAC group (77\% vs $56 \%, p=0.015)$ but they were more frequently fit for adjuvant or palliative treatment ( $60 \%$ vs $46 \%, p=0.008)$. While the overall survival of EOPC was similar to older PDAC patients with no statistically significant difference, EOPC patients who underwent surgical resection had a longer median overall survival of 25 months compared to 13 months for the same PDAC subpopulation. A similar finding has been observed in previous studies, with the highest survival of 41.8 months for resected cases reported by Duffy et al. [10] which has been 


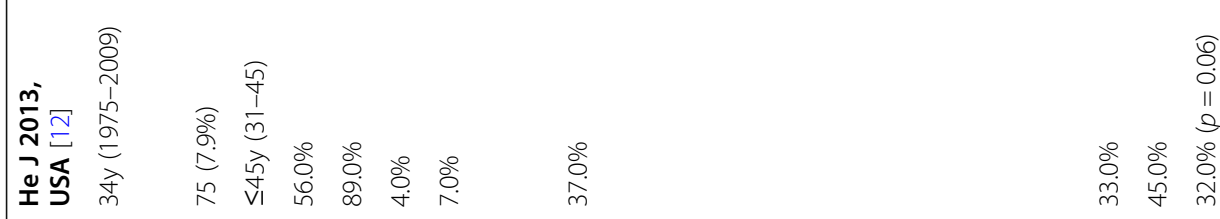

$$
\begin{aligned}
& \text { ஓें } \\
& \text { ठ্ণ }
\end{aligned}
$$

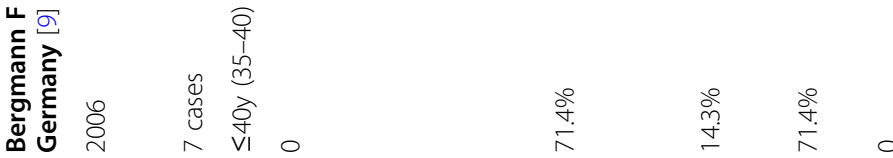

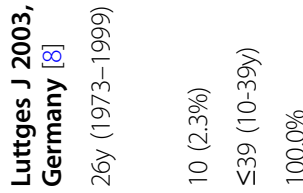

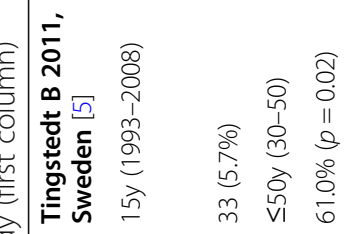

$$
\begin{aligned}
& \text { ते }
\end{aligned}
$$

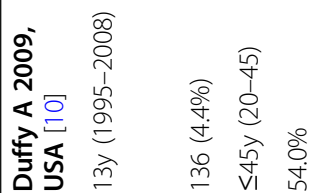

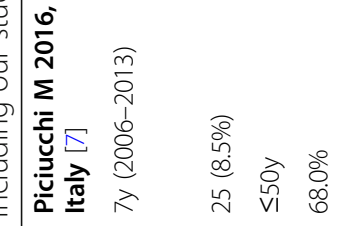

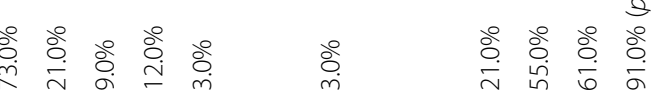

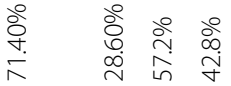

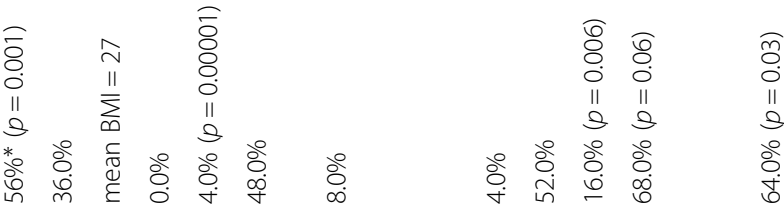

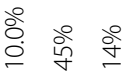

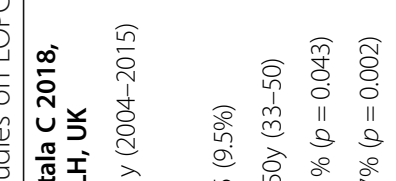

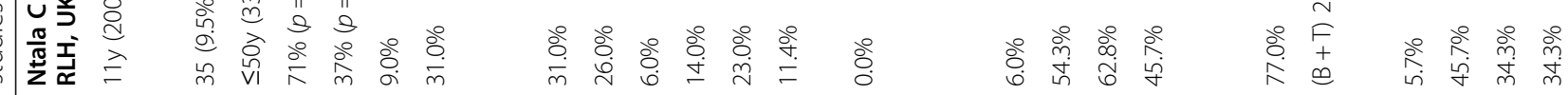

$$
\begin{aligned}
& \div
\end{aligned}
$$

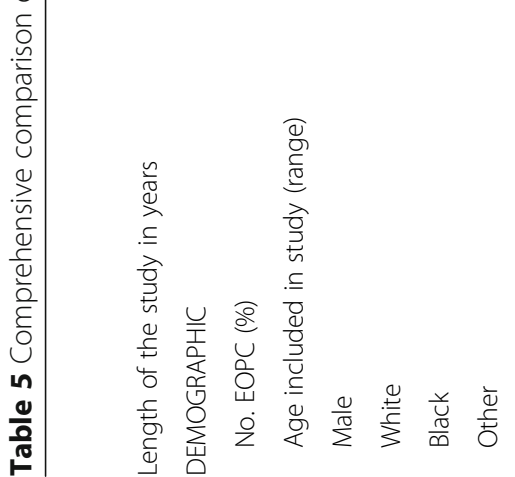

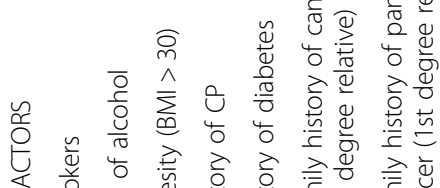

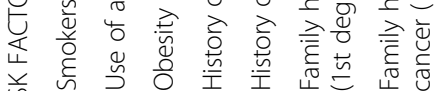

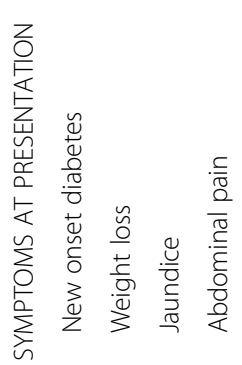

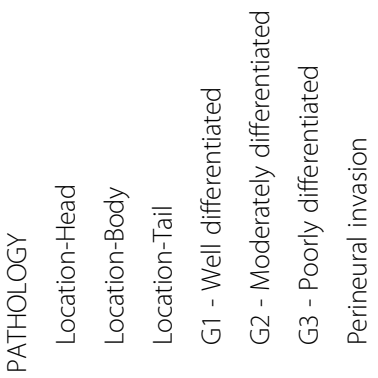

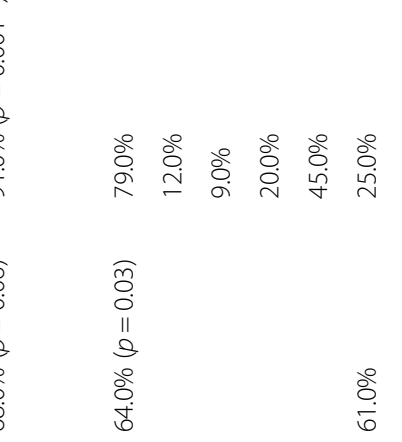$$
\Xi
$$ 


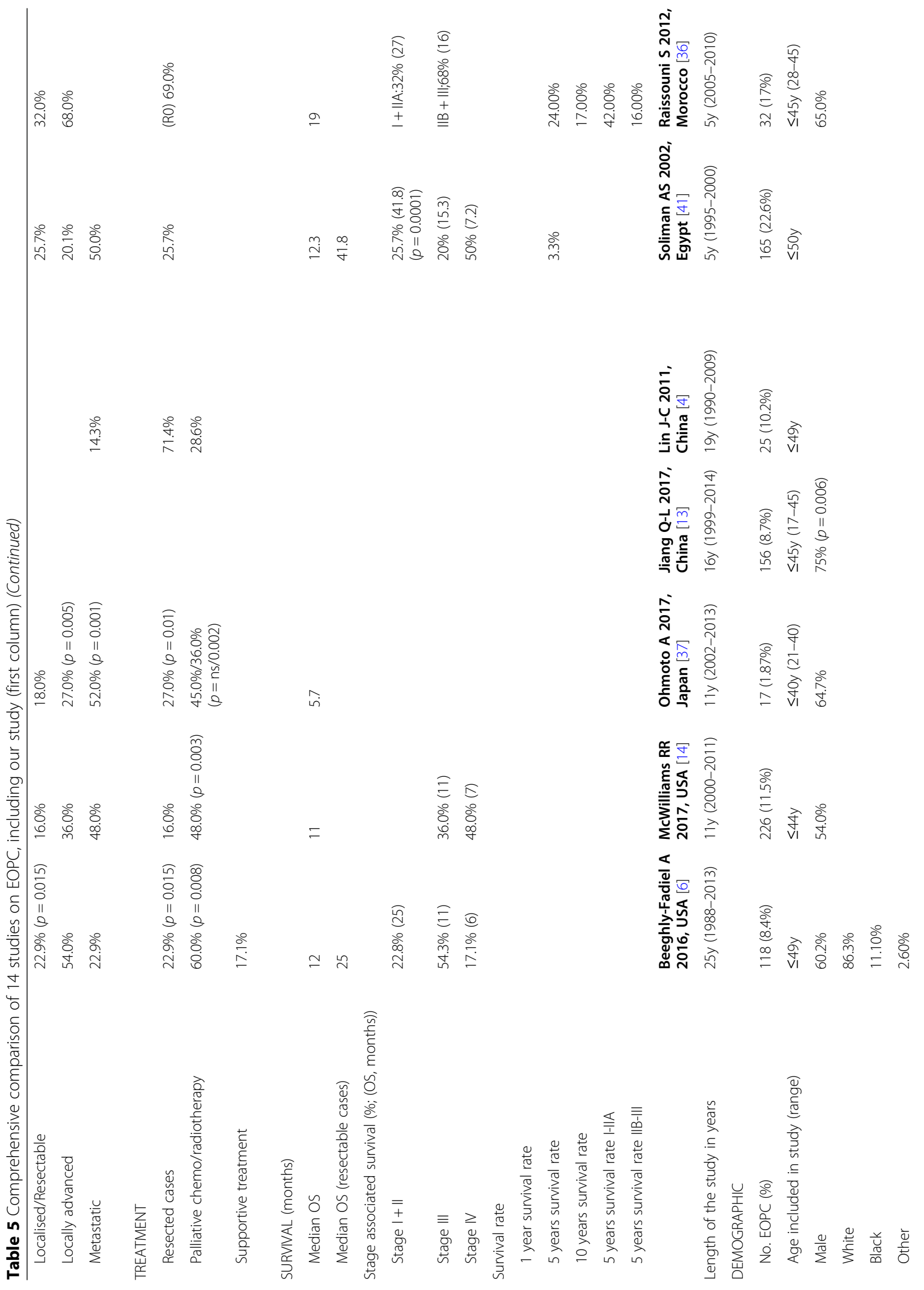


$\stackrel{\leftrightarrow}{\stackrel{0}{ }} \quad$ oे

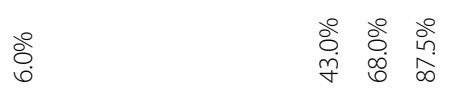

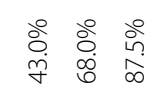

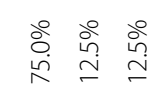

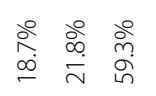

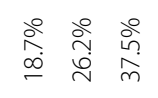

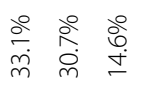

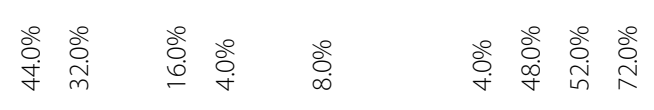

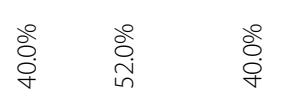

Ð

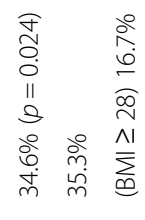

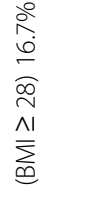

है

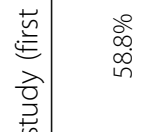

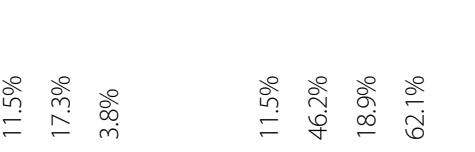

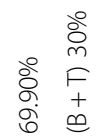

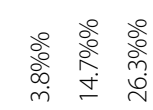

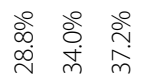

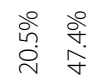

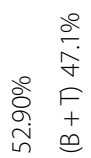

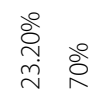

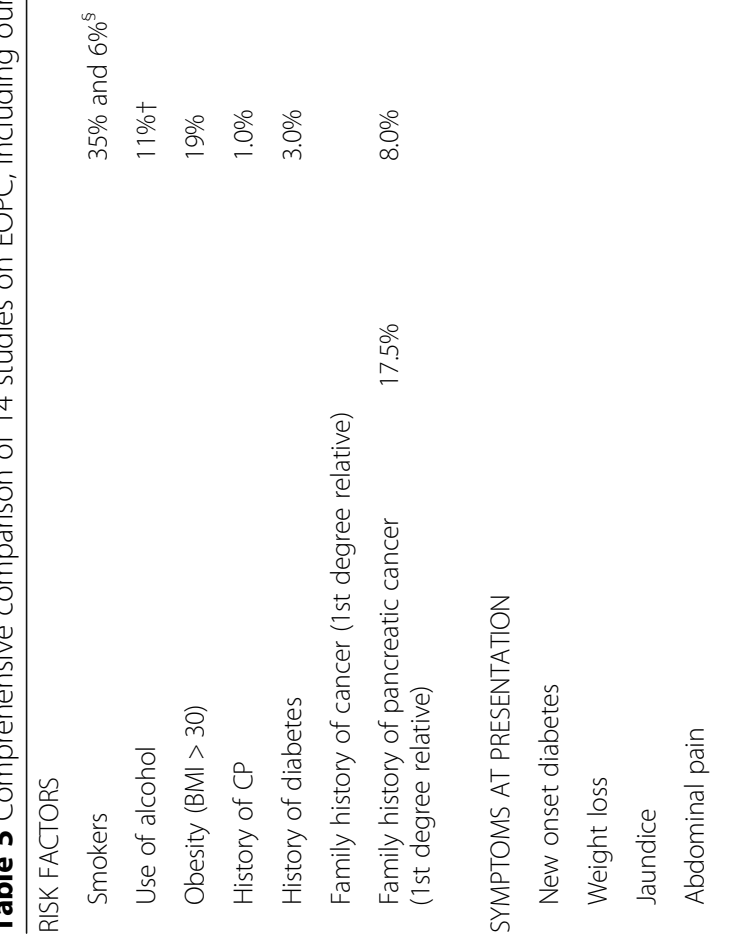

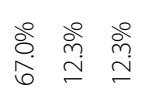

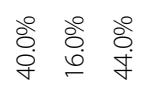

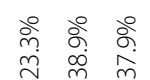

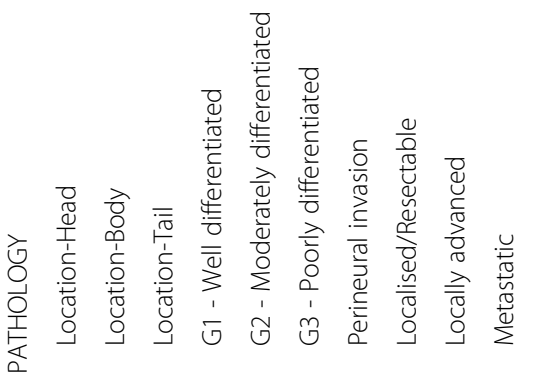

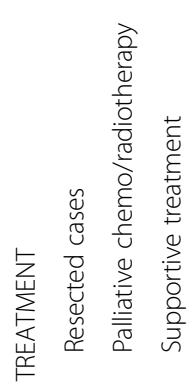


Ntala et al. BMC Gastroenterology (2018) 18:139

Page 10 of 12

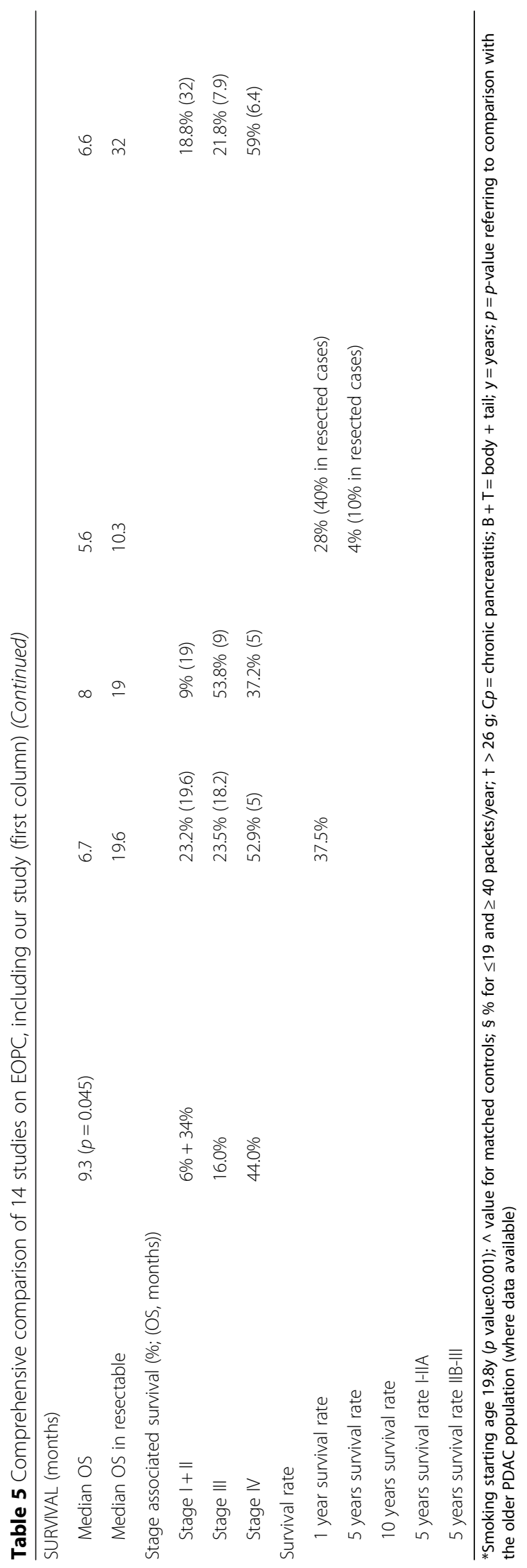


attributed to young people having fewer comorbidities and being more suitable candidates for surgery and adjuvant chemotherapy [10, 12, 13, 36, 37]. Furthermore, He et al. also showed that EOPC patients had fewer post-operative complications [12] and McWilliams et al., [14] attributed the better survival rate among young people to a multitude of factors, including race, sex, year of diagnosis, stage of disease, tumour location and treatment [14].

Our study adds to a growing body of literature on the demographic and clinicopathological characteristics of EOPC patients, using contemporary classification and staging manuals. There are some limitations to our study: firstly, the disproportionate sample size of the two comparison groups, EOPC and older PDAC, although reflecting the general incidence of the disease and unavoidable, may have contributed to statistical errors in our analysis. In addition, the retrospective nature of the study has its own pitfalls, which include possible omission of patients that did not have a tissue diagnosis, and review of medical records with sometimes incomplete data. Finally, the study was conducted in a single tertiary expert centre with referred cases and may overrepresent the patients that were suitable to undergo tissue biopsy prior to receiving more aggressive treatment. Enlarging the data set through a multi-centre collaborative approach might produce more robust results.

\section{Conclusions}

In conclusion, we present the data from a retrospective study of histologically confirmed PDAC patients over an 11-year period establishing for the first time the demographic and clinicopathological characteristics of EOPC in the multinational PDAC population inhabiting the greater London area. Our results showed demographic differences between EOPC and older PDAC patients, but no difference in association with any currently known risk factors for pancreatic cancer. EOPC patients who undergo surgery have a significantly better survival compared to their older counterparts, which reinforces the value of this therapeutic option, in combination with neoadjuvant chemotherapy/radiotherapy for downstaging of the disease. As risk factors reported previously and in our study do not point to any major differences in demographic and clinicopathological characteristics between EOPC and older PDAC patients, molecular investigations are warranted in order to understand the molecular bases for the occurrence of this highly aggressive malignancy in young populations.

\section{Abbreviations}

AJCC: American Joint Committee on Cancer; BMI: Body mass index; EOPC: Early onset pancreatic cancer; FNA: Fine needle aspiration; HP: Hereditary pancreatitis; HPB: Hepato-Pancreato-Biliary; PDAC: Pancreatic ductal adenocarinoma;
PJS: Peutz Jeghers syndrome; TNM: Tumour node metastasis; UICC: Union for International Cancer Control; WHO: World health organisation

\section{Funding}

The study was funded by Barts Charity. The funding body had no role in the design of the study and collection, analysis, and interpretation of data and in writing the manuscript.

\section{Availability of data and materials}

The datasets used and analysed during the current study are available from the corresponding author on reasonable request.

\section{Authors' contributions}

CN and TC-J conceived the study; $C N$ analysed the data and generated the results; CN, SD, RMF and TC-J contributed in revising the obtained results; $\mathrm{CN}, \mathrm{SD}$, and TC-J wrote the manuscript. All authors read and approved the final manuscript.

\section{Ethics approval and consent to participate}

The study is based on the retrospective examination of the clinical notes and review of histology reports. No patient material was accessed or reviewed. Therefore, obtaining patient consent for use of tissue in such cases is not deemed necessary according to the Human Tissue Act. The study was approved by Queen Mary University of London Review Board and London-Brent Research Ethics Committee (Reference Number: 05/Q0408/65).

Consent for publication

Not applicable.

\section{Competing interests}

The authors declare that they have no competing interests.

\section{Publisher's Note}

Springer Nature remains neutral with regard to jurisdictional claims in published maps and institutional affiliations.

\section{Author details}

${ }^{1}$ Barts Cancer Institute, Queen Mary University of London, John Vane Science Centre, Charterhouse Square, London EC1M 6BQ, UK. ${ }^{2}$ Department of Cellular Pathology, Royal London Hospital, Barts Health NHS Trust, Pathology and Pharmacy Building, Newark Street, London E1 2ES, UK.

Received: 25 April 2018 Accepted: 24 August 2018

Published online: 12 September 2018

References

1. Siegel RL, Miller KD, Jemal A. Cancer statistics, 2015. CA Cancer J Clin. 2015; 65(1):5-29.

2. Rahib L, Smith BD, Aizenberg R, Rosenzweig AB, Fleshman JM, Matrisian LM. Projecting cancer incidence and deaths to 2030: the unexpected burden of thyroid, liver, and pancreas cancers in the United States. Cancer Res. 2014; 74(11):2913-21.

3. Raimondi S, Maisonneuve P, Lowenfels AB. Epidemiology of pancreatic cancer: an overview. Nat Rev Gastroenterol Hepatol. 2009;6(12):699-708

4. Lin JC, Chan DC, Chen PJ, Chu HC, Chueh TH, Huang HH, et al. Clinical characteristics of early onset pancreatic adenocarcinoma: a medical center experience and review of the literature. Pancreas. 2011;40(4):638-9.

5. Tingstedt B, Weitkamper C, Andersson R. Early onset pancreatic cancer: a controlled trial. Ann Gastroenterol. 2011;24(3):206-12.

6. Beeghly-Fadiel A, Luu HN, Du L, Shi C, McGavic DP, Parikh AA, et al. Early onset pancreatic malignancies: clinical characteristics and survival associations. Int J Cancer. 2016;139(10):2169-77.

7. Piciucchi M, Capurso G, Valente R, Larghi A, Archibugi L, Signoretti M, et al. Early onset pancreatic cancer: risk factors, presentation and outcome. Pancreatology. 2015;15(2):151-5.

8. Luttges J, Stigge C, Pacena M, Kloppel G. Rare ductal adenocarcinoma of the pancreas in patients younger than age 40 years. Cancer. 2004;100(1): 173-82.

9. Bergmann F, Aulmann S, Wente MN, Penzel R, Esposito I, Kleeff J, et al. Molecular characterisation of pancreatic ductal adenocarcinoma in patients under 40. J Clin Pathol. 2006;59(6):580-4. 
10. Duffy A, Capanu M, Allen P, Kurtz R, Olson SH, Ludwig E, et al. Pancreatic adenocarcinoma in a young patient population--12-year experience at memorial Sloan Kettering Cancer center. J Surg Oncol. 2009;100(1):8-12.

11. Liszka L, Pajak J, Mrowiec S, Zielinska-Pajak E, Golka D, Lampe P. Precursor lesions of early onset pancreatic cancer. Virchows Arch. 2011;458(4):439-51.

12. He J, Edil BH, Cameron JL, Schulick RD, Hruban RH, Herman JM, et al. Young patients undergoing resection of pancreatic cancer fare better than their older counterparts. J Gastrointest Surg. 2013;17(2):339-44.

13. Jiang QL, Zhang SS, Chen YT, Zhang JW, Wang CF. Risk factors for earlyonset pancreatic cancer patients, and survival analysis. Int J Clin Exp Med. 2017;10(6):9416-23.

14. McWilliams RR, Maisonneuve P, Bamlet WR, Petersen GM, Li D, Risch HA, et al. Risk factors for early-onset and very-early-onset pancreatic adenocarcinoma: a pancreatic Cancer case-control consortium (PanC4) analysis. Pancreas. 2016; 45(2):311-6

15. Lynch HT, Smyrk T, Kern SE, Hruban RH, Lightdale CJ, Lemon SJ, et al. Familial pancreatic cancer: a review. Semin Oncol. 1996:23(2):251-75.

16. Tersmette AC, Petersen GM, Offerhaus GJ, Falatko FC, Brune KA, Goggins M, et al. Increased risk of incident pancreatic cancer among first-degree relatives of patients with familial pancreatic cancer. Clin Cancer Res. 2001;7(3):738-44

17. James TA, Sheldon DG, Rajput A, Kuvshinoff BW, Javle MM, Nava HR, et al. Risk factors associated with earlier age of onset in familial pancreatic carcinoma. Cancer. 2004;101(12):2722-6.

18. Kharazmi E, Fallah M, Sundquist K, Hemminki K. Familial risk of early and late onset cancer: nationwide prospective cohort study. BMJ. 2012;345:e8076.

19. Lowenfels AB, Maisonneuve P, Cavallini G, Ammann RW, Lankisch PG, Andersen JR, et al. Pancreatitis and the risk of pancreatic cancer. International pancreatitis study group. N Engl J Med. 1993;328(20):1433-7.

20. Lowenfels AB, Maisonneuve P, DiMagno EP, Elitsur Y, Gates LK Jr, Perrault J, et al. Hereditary pancreatitis and the risk of pancreatic cancer. International hereditary pancreatitis study group. J Natl Cancer Inst. 1997;89(6):442-6.

21. Brand RE, Lynch HT. Hereditary pancreatic adenocarcinoma. A clinical perspective. Med Clin North Am. 2000;84(3):665-75.

22. Kastrinos F, Mukherjee B, Tayob N, Wang F, Sparr J, Raymond VM, et al. Risk of pancreatic cancer in families with lynch syndrome. JAMA. 2009;302(16): 1790-5

23. Bowlby LS. Pancreatic adenocarcinoma in an adolescent male with PeutzJeghers syndrome. Hum Pathol. 1986;17(1):97-9.

24. Thatcher BS, May ES, Taxier MS, Bonta JA, Murthy L. Pancreatic adenocarcinoma in a patient with Peutz-Jeghers syndrome--a case report and literature review. Am J Gastroenterol. 1986;81(7):594-7.

25. Everhart J, Wright D. Diabetes mellitus as a risk factor for pancreatic cancer. A meta-analysis JAMA. 1995;273(20):1605-9.

26. Luo J, Iwasaki M, Inoue M, Sasazuki S, Otani T, Ye W, et al. Body mass index, physical activity and the risk of pancreatic cancer in relation to smoking status and history of diabetes: a large-scale population-based cohort study in Japan--the JPHC study. Cancer Causes Control. 2007;18(6):603-12.

27. Luo J, Nordenvall C, Nyren O, Adami HO, Permert J, Ye W. The risk of pancreatic cancer in patients with gastric or duodenal ulcer disease. Int J Cancer. 2007; 120(2):368-72.

28. Raimondi S, Maisonneuve P, Lohr JM, Lowenfels AB. Early onset pancreatic cancer: evidence of a major role for smoking and genetic factors. Cancer Epidemiol Biomark Prev. 2007;16(9):1894-7.

29. Maitra A, Hruban RH. Pancreatic cancer. Annu Rev Pathol. 2008:3:157-88.

30. Brand RE, Greer JB, Zolotarevsky E, Brand R, Du H, Simeone D, et al. Pancreatic cancer patients who smoke and drink are diagnosed at younger ages. Clin Gastroenterol Hepatol. 2009;7(9):1007-12.

31. Genkinger JM, Spiegelman D, Anderson KE, Bergkvist $L$, Bernstein $L$, van den Brandt PA, et al. Alcohol intake and pancreatic cancer risk: a pooled analysis of fourteen cohort studies. Cancer Epidemiol Biomark Prev. 2009;18(3):765-76.

32. Lin G, Zeng Z, Wang X, Wu Z, Wang J, Wang C, et al. Cholecystectomy and risk of pancreatic cancer: a meta-analysis of observational studies. Cancer Causes Control. 2012;23(1):59-67.

33. Becker AE, Hernandez YG, Frucht H, Lucas AL. Pancreatic ductal adenocarcinoma: risk factors, screening, and early detection. World J Gastroenterol. 2014;20(32): 11182-98.

34. Gomez-Rubio P, Zock JP, Rava M, Marquez M, Sharp L, Hidalgo M, et al. Reduced risk of pancreatic cancer associated with asthma and nasal allergies. Gut. 2017:66(2):314-22.
35. Edge SB, Compton CC. The American joint committee on Cancer: the 7th edition of the AJCC cancer staging manual and the future of TNM. Ann Surg Oncol. 2010;17(6):1471-4.

36. Raissouni S, Rais G, Mrabti H, Raissouni F, Mouzount H, Aitelhaj M, et al. Pancreatic adenocarcinoma in young adults in a moroccan population. J Gastrointest Cancer. 2012:43(4):607-11.

37. Ohmoto A, Yachida S, Kubo E, Takai E, Suzuki M, Shimada K, et al. Clinicopathologic features and germline sequence variants in young patients $(</=40$ years old) with pancreatic ductal adenocarcinoma. Pancreas. 2016;45(7):1056-61.

38. Miller BA, Kolonel LN, Bernstein L, Young Jr. JL, Swanson GM, West D, et al. Racial/Ethnic Patterns of Cancer in the United States 1988-1992, National Cancer Institute. Bethesda, MD, 1996.; 1996 1996. Contract No.: No. 96-4104.

39. Howe GR, Jain M, Burch JD, Miller AB. Cigarette smoking and cancer of the pancreas: evidence from a population-based case-control study in Toronto. Canada Int J Cancer. 1991;47(3):323-8.

40. Silverman DT, Dunn JA, Hoover RN, Schiffman M, Lillemoe KD, Schoenberg JB, et al. Cigarette smoking and pancreas cancer: a case-control study based on direct interviews. J Natl Cancer Inst. 1994;86(20):1510-6.

41. Soliman AS, El-Ghawalby N, Ezzat F, Bondy ML, Soultan A, Abdel-Wahab M, et al. Unusually high rate of young-onset pancreatic cancer in the East Nile Delta region of Egypt. Int J Gastrointest Cancer. 2002;32(2-3):143-51.

42. Bartsch DK, Gress TM, Langer P. Familial pancreatic cancer--current knowledge. Nat Rev Gastroenterol Hepatol. 2012;9(8):445-53.

43. Del Chiaro M, Menicagli M, Campani D, Funel N, Pollina LE, Decarli N, et al. Sporadic pancreatic ductal carcinoma in patient aged less than 40 years. Pancreas. 2004;29(4):336

\section{Ready to submit your research? Choose BMC and benefit from:}

- fast, convenient online submission

- thorough peer review by experienced researchers in your field

- rapid publication on acceptance

- support for research data, including large and complex data types

- gold Open Access which fosters wider collaboration and increased citations

- maximum visibility for your research: over $100 \mathrm{M}$ website views per year

At BMC, research is always in progress.

Learn more biomedcentral.com/submissions 